\title{
AS CONTRIBUIÇÕES DO TRABALHO DE CAMPO PARA O ENSINO DE GEOGRAFIA - O PAPEL DA FORMAÇÃO DE PROFESSORES
}

\author{
The contributions of field work in Geography teaching - the role of teacher's training. \\ Las contribuciones del trabajo en terreno para la enseñanza de Geografía - el rol de la \\ formación de profesores
}

Domitila Theil Radtke

*Doutoranda do Programa de Pós-Graduação em Geografia da Universidade Federal de Goiás (UFG) domitilatr@gmail.com

Recebido em 20/10/2019. Aceito para publicação em 20/10/2019.

Versão online publicada em 10/11/2019 (http://seer.ufrgs.br/paraonde)

\section{Resumo:}

O artigo tem por objetivo ressaltar a importância dos trabalhos de campo e dos Estudos do Meio no ensino de Geografia, além de discutir a necessidade de uma formação inicial que prepare o professor de Geografia para realizar tais atividades com qualidade. A metodologia deste trabalho é marcada pela busca de referenciais teóricos sobre trabalho de campo (ALENTEJANO e ROCHA-LEÃO, 2006; SERPA, 2006) trabalho de campo para o ensino ou Estudos do Meio (MORAIS e LIMA, 2018; PONTUSCHKA, 2013; LOPES e PONTUSCHKA, 2009), formação de professores (SHULMAN, 1987; GROSSMAN, WILSON e SHULMAN, 2005) e ensino de Geografia (CAVALCANTI, 1998; MORAIS, 2013). Acredita-se que, para que o professor de Geografia desenvolva trabalhos de campo significativos, que integre os componentes físico-naturais e sociais do espaço geográfico, é necessáriaa mobilização de seus conhecimentos específicos do conteúdo, assim como os seus conhecimentos pedagógicos. Para isto, é fundamental uma formação inicial que desenvolva trabalhos de campo numa perspectiva crítica e não fragmentada da Geografia, para que esta metodologia dê conta da complexidade do espaço geográfico o que, por sua vez, exige do professorconhecimento didático do conteúdo. Além disso, contextualiza-se a importância destas questões estarem inseridas nas praticas espaciais cotidianas dos alunos, para que as mesmas ganhem novos significados de cidadania e autonomia.

Palavras-chave: Trabalho de campo. Metodologia. Formação de Professores. Ensino de Geografia.

\begin{abstract}
:
The article aims to highlight the importance of fieldwork and Milieu Analysis in Geography teaching, and moreover to discuss the need for an initial training that allows Geography teachers to perform such activities with quality. The methodology of this study is marked by the search for theoretical references about fieldwork (ALENTEJANO and ROCHA-LEÃO, 2006; SERPA, 2006), fieldwork for teaching or Milieu Analysis (MORAIS and LIMA, 2018; PONTUSCHKA, 2013; LOPES and PONTUSCHKA, 2009), the training of teachers (SHULMAN, 1987; GROSSMAN, WILSON and SHULMAN, 2005) and Geography teaching (CAVALCANTI, 1998; MORAIS, 2013). It is believed that, for the Geography teacher to develop significant fieldwork that integrates the physical-natural and social components of the geographical space, it is necessary to mobilize his specific knowledge of the subject, as well as his pedagogical knowledge. For this, an initial formation that develops fieldwork in a critical and non-fragmented perspective of Geography is crucial, so that this methodology can account for the complexity of the geographical space, which, in turn, demands from the teacher the didactic knowledge of the subject. In addition, the importance of these questions becomes embedded in the students' daily spatial practices, so that such questions acquire
\end{abstract}


new meanings of citizenship and autonomy.

Key-words:Fieldwork. Methodology.Training of teachers.Geographyteaching.

\begin{abstract}
Resumen:
El artículo científico tiene por objetivo mostrar la importancia de los trabajos en terreno y de Estudio del Medio de la Geografía y también discutir la necesidad de una formación inicial que prepare el profesor de Geografía para realizar tales actividades con calidad.La metodología del trabajo es marcada por la búsqueda de referenciales teóricos sobre trabajo en terreno (ALENTEJANO y ROCHA-LEÃO, 2006; SERPA, 2006) trabajo en terreno para o la enseñanza o Estudios del Medio (MORAIS y LIMA, 2018; PONTUSCHKA, 2013; LOPES E PONTUSCHKA, 2009), formación de profesores (SHULMAN, 1987; GROSSMAN, WILSON y SHULMAN, 2005) y enseñanza de Geografía (CAVALCANTI, 1998; MORAIS, 2013).Se cree que, para el profesor de Geografía desarrolle trabajos en terreno significativos, que integren los componentes físicos, naturales y sociales del espacio geográfico, es necesario la movilización de sus conocimientos específicos del contenido, como también sus conocimientos pedagógicos.Para ello, es fundamental una formación inicial que desarrolle trabajos en terreno en una perspectiva crítica y no fragmentada de la Geografía, para que esa metodología alcance la complejidad del espacio geográfico lo que, por su vez, exige del profesor el conocimiento didáctico del contenido.Además, se contextualiza la importancia de que esas cuestiones estén insertadas en las prácticas espaciales del día a día de los alumnos, para que ellas ganen nuevos significados de ciudadanía y autonomía.
\end{abstract}

Palabras-clave:Trabajo en terreno. Metodología. Formación de profesores. Enseñanza de Geografía.

\title{
1 Introdução
}

O trabalho do professor de Geografia, especificamente, em relação às suas metodologias, práticas e instrumentos de pesquisa e ensino permeiam o debate acadêmico em que a autora está inserida, juntamente com as indagações que as pesquisas $e$ os projetos a qual está associada, até o momento, levantam questionamentos sobre o papel do professor na mediação de seus conhecimentos teórico-metodológicos sobre determinado conteúdo geográfico. Assim, se indaga sobre a importância destes conhecimentos na formação inicial do professor, especialmente, em relação àqueles voltados ao exercício de propostas metodológicas como a de trabalhos de campo no ensino de Geografia.

Pretende-se aqui, demonstrar as potencialidades dos trabalhos de campo no processo de ensino e aprendizagem em Geografia, como metodologia que proporcione o desenvolvimento dos conhecimentos teórico-metodológicos doprofessor, de forma integradora, em relação aos conceitos geográficos. Isto, desde que, sejam vistos de forma a considerar tanto os componentes físico-naturais como as temáticas sociais do espaço, no qual consideramos indissociáveis.

Acredita-se na importância dos trabalhos de campo na produção do conhecimento geográfico, assim como este serve como instrumento chave para a superação das ambiguidades geográficas, "não priorizando nem a análise dos chamados fatores naturais nem dos fatores humanos", não havendo, também, separação entre teoria e metodologia (SERPA, 2006, p.7).

ParaOnde!?, Porto Alegre, v.12 n.2, p.81-88, 2019. http://seer.ufrgs.br/paraonde Edição Especial -III Colóquio de Pesquisadores em Geografia Física Ensino 
O interesse pela temática dos trabalhos de campo no ensino de Geografia decorre da trajetória acadêmica e pessoal da autora, visto que se trabalhou com Estudos do Meio - que contém o trabalho de campo como uma de suas etapas - desde sua formação inicial no curso de licenciatura em Geografia (2011-2014). Desde então, realizou-se o trabalho de conclusão de curso (TCC) sobre esta metodologia e a percepção da paisagem em projetos disciplinares e interdisciplinares no Programa Institucional de Bolsas de Iniciação à Docência (PIBID). Assim como, posteriormente,desenvolveu-se a dissertação de mestrado sobre a historicidade deste"método de ensino", (LOPES e PONTUSCHKA, 2009, p.174) ou também concebido como uma "metodologia de ensino e pesquisa", (RADTKE, 2017).

Os Estudos do Meio são as primeiras atividades desenvolvidas, para o processo de ensino-aprendizagem na educação básica, mais próximas ao que concebemos por atividades de trabalhos de campo, interdisciplinares ou não, na atualidade. Estas atividades estão relacionadas à historicidade do geógrafo ÉliséeReclus e seu vínculo com a Escola Moderna de Franscesc Ferrer i Guàrdia que, por sua vez, se relacionada ao que entendemos, hoje, por Pedagogia Libertária (RADTKE, 2017).

Este artigo se refere ao trabalho de campo como metodologia de ensino e pesquisa em Geografia. Este recorte se dá pela necessidade de pensar a formação dos professores da área. Entendemos que é necessária, mesmo para desenvolver uma prática interdisciplinar como os Estudos do Meio, uma formação inicial adequada que possibilite, por sua vez, a mobilização de um conjunto de conhecimentos docentes correspondentes a este componente curricular.

Acreditamos que seja necessário, para um desenvolvimento significativo dos trabalhos de campo no ensino básico, que o professor de Geografia seja capaz de mobilizar tanto seu conhecimento teórico do conteúdo trabalhado, como o de mobilizar seus conhecimentos pedagógicos do conteúdo, ou seja, ser capaz de consolidar seu conhecimento didático do conteúdo (SHULMAN, 2014). E, para que isto seja possível, é fundamental aos professores de Geografia uma formação inicial que se volte para a construção e o desenvolvimento destes conhecimentos docentes.

Neste sentido, objetiva-se apresentar a importância da formação inicial que dê suporte ao professor para todas estas questões. Da necessidade da valorização dos trabalhos de campos para o ensino de Geografia, ao mesmo tempo em que reconhece a necessidade deste professor em conseguir desenvolver uma metodologia que dê conta de trabalhar e produzir conhecimento geográfico dentro e fora da sala de aula, ou seja, ser capaz de desenvolver trabalhos de campo embasados nos seus conhecimentos didáticos do conteúdo.

Este trabalho, assim como exposto anteriormente, é construção de uma caminhada acadêmica e pessoal da autora. Logo, os primeiros referenciais para a pesquisa surgem da necessidade de conhecer a temática para, posteriormente, aprofundar teórico, histórico e metodologicamente os trabalhos de campo na ciência geográfica e, por conseguinte, da necessidade de ir além dos procedimentos técnicos e metodológicos do trabalho de campo e adentrar as questões pedagógicas desta metodologia. Sendo assim, apontamos a necessidade de desenvolver trabalhos de campo para além da pesquisa acadêmica, ou seja, voltados, adequadamente, à formação inicial de um professor de Geografia. Isto significa desenvolver trabalhos de campo preocupados e direcionados à formação de futuros profissionais da Educação Básica.

ParaOnde!?, Porto Alegre, v.12 n.2, p.81-88, 2019. http://seer.ufrgs.br/paraonde Edição Especial -III Colóquio de Pesquisadores em Geografia Física Ensino 
Acreditamos que pesquisa e ensino precisam caminhar lado a lado, buscando um diálogo contínuo que, por sua vez, proporciona uma formação mais rica e significativa ao profissional de Geografia. Segundo Demo (2006) é preciso que estas duas vertentes continuem juntas não só na formação acadêmica, mas, também, durante toda a atuação profissional do professor.

Desta forma, a metodologia do trabalho é marcada pela busca de referenciais teóricos sobre trabalho de campo (ALENTEJANO \& ROCHA-LEÃO, 2006; SERPA, 2006) trabalho de campo e ensino ou Estudos do Meio (MORAIS e LIMA, 2018; PONTUSCHKA, 2013; LOPES e PONTUSCHKA, 2009; RADTKE, 2017), formação de professores (SHULMAN, 1987; GROSSMAN, WILSON e SHULMAN, 2005) e ensino de Geografia (CAVALCANTI, 1998; MORAIS, 2013). Apresentando-se, assim, como um trabalho teórico com perspectiva de instigar questões voltadas à formação inicial e de colaborar para uma atuação docente voltada ao desenvolvimento de trabalhos de campo na Educação Básica.

\section{Desenvolvimento}

Entende-se o espaço geográfico, como algo longe de ser fragmentado. Ele é na verdade, segundo Milton Santos (2009), um conjunto indissociável de sistemas de objetos e sistemas de ações. Da mesma forma, acreditamos que são indissociáveis todos os aspectos e componentes deste objeto de estudo da ciência geográfica. Um ensino que não atenda a integração destes componentes acaba por apresentar de forma fragmentada os conteúdos de Geografia que, por sua vez, reflete na construção dos conhecimentos geográficos por parte dos alunos.

O trabalho de campo, como método ou metodologia de pesquisa e ensino, é capaz de proporcionar um ensino que contemple uma aprendizagem mais significativa e integradora dos conteúdos geográficos, principalmente, aqui, no que se refere ao ensino dos componentes físico-naturais. Da mesma forma que o Estudo do Meio, enquanto uma importante metodologia interdisciplinar, (PONTUSCHKA, 2013; LOPES e PONTUSCHKA, 2009), é capaz depossibilitar um trabalho que busque o rompimento de um ensino fragmentado.

Os trabalhos de campo, no âmbito da formação inicial dos professores de Geografia, costumam ser desenvolvidos de forma fragmentada devido às disciplinas de conhecimentos específicos (Hidrografia, Geologia, Geomorfologia). Esta característica não é vista, aqui, como uma maneira "correta ou errada", porém, acreditamos não ser suficiente enquanto momento de formação de um futuro professor da Educação Básica. Nem sempre um trabalho de campo apresenta o conteúdo de forma fragmentada, mas quando se tem esta sorte, geralmente, não é previsto um planejamento pedagógico para e com os alunos. Perceber-se agente passivo neste processo podedesestimular o aluno a desenvolver estas práticas em suas futuras aulas ou, mais ainda, pode estimular o aluno a desenvolvê-lo da mesma maneira que seu professor universitário desenvolve.

$\mathrm{E}$, como apontado, os trabalhos de campo que não se preocupam com o processo de ensino-aprendizagem e, consequentemente, com a formação de conhecimentos docentes necessários ao seu desenvolvimento são, na verdade, trabalhos de campo para a pesquisa.

ParaOnde!?, Porto Alegre, v.12 n.2, p.81-88, 2019. http://seer.ufrgs.br/paraonde Edição Especial -III Colóquio de Pesquisadores em Geografia Física Ensino 
Assim, acreditamos que não é só importante compreender que os componentes físico-naturais e sociais são indissociáveis, mas, também, compreender como trabalhá-los desta maneira. É neste sentido que o trabalho de campo e/ou o Estudo do Meio pode cumprir com um importante papel no caminho metodológico escolhido pelo professor de Geografia.

Estes aspectos vão ao encontro das pesquisas realizadas por Morais e Lima (2018) que demonstram que alguns professores de Geografia não desenvolvem trabalhos de campo não só pelas várias dificuldades escolares, mas, também, devido à dificuldade que sentem ao realizar o recorte analítico, especificamente, quando ele é referente aos componentes físico-naturais do espaço. Ou seja, as dificuldades dos professores não estão relacionadas somente no como realizar os trabalhos de campo, seja pedagógica e metodologicamente, mas, também em relação ao o que, ao conteúdo geográfico específico a ser trabalhado.

São dificuldades relativas aos conhecimentos pedagógicos e, também, aos conhecimentos do conteúdo, o que torna mais complicado a atuação do professor quando pensamos no desafio que é este conjunto de aspectos no âmbito dos conhecimentos didáticos do conteúdo.

Desta forma, é fundamental que os professores de Geografia, além de compreenderem a importância dessa integração, saibam desenvolvê-la com seus alunos durante as práticas escolares. Que outra maneira senão trabalhar isto desde sua formação inicial? Logo, é de fundamental que este conjunto de conhecimentos docentes seja desenvolvido durante o curso de licenciaturaem Geografia e que sua mobilização perpetue durante toda a caminhada profissional do docente da Educação Básica.

Acreditamos que, para que o professor realize trabalhos de campo que integrem os componentes físico-naturais e sociais do espaço é salutar que ele possua as condições necessárias para a construção e mobilização dos conhecimentos específicos do conteúdo e dos conhecimentos pedagógicos. Portanto, para um processo de ensino-aprendizagem significativo, o professor deve mobilizar dialogicamente este conjunto de conhecimentos específicos e pedagógicos.

Esta conjunção é o que Shulman (2015) denomina deconhecimento pedagógico do conteúdo que, por sua vez, é indispensável à sua atuação profissional.É neste sentido que o autor (1987, p.205) aponta a existência de uma base de conhecimento para lecionar e que, portanto, "o ensino necessariamente começa com o professor entendendo o que deve ser aprendido e como deve ser ensinado".

Outro aspecto importante a ser trazido é o envolvimento destas atividades com as práticas espaciais cotidianas dos alunos, para que as mesmas façam sentido na vida dos discentes.Para Cavalcanti (1998) a prática cotidiana dos alunos é plena de espacialidade e é papel da escola trabalhar com esse conhecimento, ou seja, trabalhar através de práticas reflexivas e críticas, tornando possível ampliar e qualificar as práticas destes alunos. Estas atividades, para a autora, são fundamentais para o exercício da cidadania destes jovens e, estas, estão impregnadas das práticas cotidianas e envoltas no lugar, enquanto categoria geográfica.

Considerando a Escola como um lugar que desenvolva no aluno a capacidade de interpretar o espaço em que vive e de perceber-se como agente transformador de sua realidade, entendemos que se faz necessário estes questionamentos e discussões sobre

ParaOnde!?, Porto Alegre, v.12 n.2, p.81-88, 2019. http://seer.ufrgs.br/paraonde Edição Especial -III Colóquio de Pesquisadores em Geografia Física Ensino 
o conhecimento didático do conteúdo no processo de ensino-aprendizagem, com ênfase, aqui, no desenvolvimento dos trabalhos de campo. Isto para que os docentes deem conta de trabalhar com questões complexas de forma integradora e significativa para o aluno, considerando que o espaço geográfico, objeto da ciência geográfica, é complexo e as práticas espaciais cotidianas precisam ser ressignificadas.

O trabalho de campo seria, portanto, capaz de colaborar para tentativa de superação desta fragmentação geográfica, na medida em que colabora com o professor que considera as complexidades do espaço geográfico e busca, atravésde atividades mediadoras da teoria e prática, escala local e global, pesquisa e ensino, (ALENTEJANO E ROCHA-LEÃO, 2006), uma aprendizagem mais significativa ao seu aluno. Estas características dos trabalhos de campo, assim como dos Estudos do Meio, (PONTUSCHKA, 2013; LOPES e PONTUSCHKA, 2009), potencializam o processo de ensino-aprendizagem de Geografia e valorizam o cotidiano do aluno, na medida em que o professor poderá partir das problemáticas e da realidade escolar in loco para 0 desenvolvimento do conteúdo geográfico.

Através destas metodologias o professor de Geografia encontrará meios que possibilitem a produção de conhecimentos geográficos significativo. A análise, leitura e interpretação do espaço pelo aluno são fundamentais para a construção da aprendizagem geográfica. É neste contexto que a temática da formação de professores, da mobilização dos conhecimentos teóricos e dos conhecimentos pedagógicos, merece destaque dentro da pesquisa da autora sobre os trabalhos de campo para a pesquisa e para o ensino de Geografia, além de destacar a importância de atividades que possibilitam o estudoin locoe potencializam a mediação teoria e prática, sujeito e sua realidade, conhecimento didático e do conteúdo, entre outros.

\section{Considerações finais}

Acredita-se que investigar esta temática é relevante tanto para a Geografia, enquanto conhecimento acadêmico, quanto para a formação de um conhecimento voltado à Geografia Escolar, visto a ênfase dada aos trabalhos de campo para o processo de ensino-aprendizagem na Educação Básica. Assim como, para os conhecimentos didáticos do conteúdo, do docente,necessários ao desenvolvimento dos trabalhos de campo na Geografia Escolar, ou seja, é preciso saber mediar o conhecimento do conteúdo específico (clima, solo, relevo, entre outros, no caso dos componentes físico-naturais) e o conhecimento pedagógico necessário para trabalhar este conteúdo e/ou componente geograficamente. Nos trabalhos de campo isto significa saber como desenvolvê-los voltados à aprendizagem de uma Geografia Escolar.

Desta forma, compreendemos que o papel da formação inicial do professor de Geografia é fundamental no que diz respeito ao desenvolvimento de metodologias que tratem da integração dos componentes físico-naturais e sociais do espaço, de maneira que o professor compreenda o que é preciso aprender para realizar tal atividade quanto e com a mesma importância - o que é preciso para e como ensinar.

Estudar sobre o assunto, também tem colaborado na construção da formação pessoal e profissional enquanto futura professora de Geografia, visto que a autora se identifica com o tema desde a graduação e busca aprofundar e gerar novos

ParaOnde!?, Porto Alegre, v.12 n.2, p.81-88, 2019. http://seer.ufrgs.br/paraonde Edição Especial -III Colóquio de Pesquisadores em Geografia Física Ensino 
conhecimentos desde então, seja no que se refere aos Estudos do Meio como, atualmente, aos trabalhos de campo na Geografia Escolar que, aqui, dá ênfase na formação de professores. Isto porque a pesquisa é vista como um ato de autonomia e liberdade. É capaz de colaborar tanto para a formação acadêmica como a pessoal, social e científica.

\section{Referências}

ALENTEJANO, Paulo R. R. \& ROCHA-LEÃO, Otávio M. Trabalho de campo: uma ferramenta essencial para os geógrafos ou um instrumento banalizado? Boletim Paulista de Geografia / Seção São Paulo - Associação dos Geógrafos Brasileiros. - nº 84São Paulo: AGB, 2006. p.51-68.

CAVALCANTI, Lana de Souza. Geografia, escola e construção de conhecimentos. $6^{\text {a }}$ ed. Campinas: Papirus, 1998.

DEMO, Pedro. Pesquisa: Princípio Científico e Educativo. 12ª ed. São Paulo: Cortez, 2006.

GROSSMAN Pamela L.; WILSON Suzzane M.; SHULMAN, Lee S. Profesores de sustancia: elconocimiento de lamateria para laenseñanza. Revista de currículum y formacióndelprofesorado, 9, 2, pp. 1-25, 2005. Disponível em: <http://www.ugr.es/local/recfpro/Rev92ART2.pdf>. Acesso em: 03 de set. 2018.

LOPES, Claudivan Sanches; PONTUSCHKA, NídiaNacib. Estudo do meio: teoria e prática.Geografia (Londrina) v. 18, n. 2, 2009. Disponível em: <http://www.uel.br/revistas/uel/index.php/geografia/>. Acesso em: 10 out. 2019.

MORAIS, Eliana Marta Barbosa de. As temáticas físico-naturais no Ensino de Geografia. In: CAVALCANTI, Lana de Souza. (Org.) Temas da geografia na Escola Básica. Campinas, SP: Papirus, 2013.

MORAIS, Eliana Marta Barbosa de; LIMA, Cláudia Valéria. Trabalho de campo e ensino de Geografia: proposições metodológicas para o ensino de componentes físiconaturais do espaço na Geografia. In: MORAIS, Eliana Marta Barbosa de; ALVES, Adriana Olivia; ASCENÇÃO, Valéria de Oliveira Roque (Org.) Contribuições da Geografia Física para o ensino de Geografia. Goiânia: C\&A Alfa Comunicações, 2018.

PONTUSCHKA, NídiaNacib. O conceito de Estudo do Meio transforma-se... em tempos diferentes, em escolas diferentes, com professores diferentes. In: VESENTINI, José Willian (org). O Ensino de Geografia no século XXI. Campinas/SP: Papirus, 7ed, 2013. (p. 254 -259)

RADTKE, Domitila Theil. Estudo do Meio:uma herança da Geografia Anarquista e da Pedagogia Libertária - contribuições de Francesc Ferrer i Guàrdia e ÉliséeReclus. Dissertação (Mestrado). Instituto de Ciências Humanas, Universidade Federal de Pelotas - Pelotas/RS, 2017.

ParaOnde!?, Porto Alegre, v.12 n.2, p.81-88, 2019. http://seer.ufrgs.br/paraonde Edição Especial -III Colóquio de Pesquisadores em Geografia Física Ensino 
SANTOS, Milton (1926-2001). A Natureza do Espaço: Técnica e Tempo, Razão e Emoção. - 4⿳a .ed. 5.reimpressão - São Paulo: Editora da Universidade de São Paulo, 2009.

SERPA, Ângelo. $O$ trabalho de campo em geografia: uma abordagem teóricometodológica. Boletim Paulista de Geografia, São Paulo, no 84, p. 7-24, 2006.

SHULMAN, Lee $S$. Conhecimento e ensino: fundamentos para a nova reforma. Harvard EducationalReview, v. 57, n. 1, p. 1-22, primavera 1987.Tradução de Leda Beck e revisão técnica de Paula Louzano.In:Cadernos cenpec. São Paulo, v.4, n.2, p.196-229, dez. 2014.

Disponível

em:

<http://cadernos.cenpec.org.br/cadernos/index.php/cadernos/article/view/293/297> Acessado em: 03 de set. 2018. 